\title{
Erratum to: Meat, poultry and fish and risk of colorectal cancer: pooled analysis of data from the UK dietary cohort consortium
}

\author{
Elizabeth A. Spencer $\cdot$ Timothy J. Key $\cdot$ Paul N. Appleby $\cdot$ Christina C. Dahm • \\ Ruth H. Keogh • Ian S. Fentiman • Tasnime Akbaraly • Eric J. Brunner • \\ Victoria Burley · Janet E. Cade · Darren C. Greenwood · Alison M. Stephen • \\ Gita Mishra - Diana Kuh • Robert Luben - Angela A. Mulligan - Kay-Tee Khaw • \\ Sheila A. Rodwell
}

Published online: 13 July 2011

(C) Springer Science+Business Media B.V. 2011

\section{Erratum to: Cancer Causes Control (2010) \\ 21:1417-1425 \\ DOI 10.1007/s10552-010-9569-7}

There was an error in the algorithm used to select the controls in one of the contributing cohorts, the United Kingdom Women's Cohort Study (UKWCS), with the effect that these controls were not random. This affects 25 case-control sets ( 25 cases and 100 controls). Exclusion of these case-control sets reduced the number of cases from
579 to 554, and the number of controls from 1996 to 1896 , and caused only very small changes to the published results. For the main results as reported in the Abstract, odds ratios ( $95 \%$ confidence intervals) for a $50 \mathrm{~g} /$ day increase were $1.02(0.84-1.23)$ for red meat, 0.84 (0.64-1.11) for processed meat, $0.96(0.82-1.12)$ for red and processed meat combined, $0.83(0.66-1.04)$ for poultry, $0.91(0.69-1.21)$ for white fish, and $0.91(0.72-1.17)$ for fatty fish. The conclusions remain unchanged. The full set of revised results is available from the authors.

The online version of the original article can be found under doi:10.1007/s10552-010-9569-7.

E. A. Spencer · T. J. Key $(\bowtie) \cdot$ P. N. Appleby

Cancer Epidemiology Unit, Nuffield Department of Clinical Medicine, University of Oxford, Richard Doll Building, Oxford OX3 7LF, UK

e-mail: tim.key@ceu.ox.ac.uk

C. C. Dahm - R. H. Keogh - A. A. Mulligan - S. A. Rodwell Department of Public Health and Primary Care, Medical Research Council Centre for Nutritional Epidemiology in Cancer Prevention and Survival, Cambridge CB1 8RN, UK

\section{R. H. Keogh}

Medical Research Council Biostatistics Unit, Institute of Public Health, University of Cambridge, Cambridge CB2 OSR, UK

\section{S. Fentiman}

Academic Oncology Unit, Guy's Hospital, London SE1 9RT,

UK

\section{T. Akbaraly $\cdot$ E. J. Brunner}

Medical Research Council Unit for Lifelong Health and Ageing,

33 Bedford Place, London WC1B 5JU, UK

\author{
V. Burley · J. E. Cade · D. C. Greenwood \\ Centre for Epidemiology \& Biostatistics, University of Leeds, \\ Worsley Building, Leeds LS2 9JT, UK \\ A. M. Stephen \\ MRC Human Nutrition Research, Elsie Widdowson Laboratory, \\ Cambridge CB1 9NL, UK \\ G. Mishra · D. Kuh \\ MRC Unit for Lifelong Health and Ageing, Department of \\ Epidemiology and Public Health, University College London, \\ London WC1B 5JU, UK \\ R. Luben · K.-T. Khaw \\ Department of Public Health and Primary Care, University of \\ Cambridge, Cambridge CB1 8RN, UK
}

